up to $4 \mathrm{~mm}$. It diminishes after this age, so that in a patient over 45 years $3 \mathrm{~mm}$ or more can be considered abnormal. 48

Recently P. H. Smith and colleagues ${ }^{9}$ reported a study of all rheumatoid patients admitted to the beds of the Rheumatism Department of the Manchester Royal Infirmary between 1955 and 1964. Lateral radiographs of the cervical spine in flexion and extension were taken on 751 patients (422 females and 309 males). They were also taken on an additional 211 rheumatoid patients (146 females and 65 males) admitted to the Devonshire Royal Hospital. The films of these patients were all examined by one observer. The findings are of interest. Of these 962 patients, 150 (45 males and 105 females) had cervical luxations at one or more levels, luxation being considered to be present if a gap of $3.5 \mathrm{~mm}$ or more was seen between atlas and odontoid process on a lateral film. Twenty of the 150 patients had evidence of a spinal cord or brainstem lesion, while the remaining 130 patients (89 females and 41 males) had no evidence of neurological disease. Downward luxation of the atlas on the axis was found in 9 of these 130 patients. Of those patients with cervical luxation the average duration of rheumatoid arthritis was 12.8 years (males 8.9 , females 13.5 years).

In a follow-up period of 5-14 years after initial detection of the luxation 52 patients died, while four developed cord lesions and six symptoms suggestive of vertebral ischaemia. Initially there were 121 luxations among 84 survivors, and at follow-up just over a quarter had increased, just less than half had remained unaltered, and a quarter had either improved or recovered completely. A study of survival tables suggested that cervical luxations did not themselves shorten the lives of patients with rheumatoid arthritis but appeared to progress more favourably in patients with negative sheepcell agglutination tests than those with positive tests. As regards therapy, collars as prescribed in this series had no demonstrable effect on radiological progress of luxations, while corticosteroids appeared to have an adverse effect on forward luxations at $\mathrm{C} 1-2$.

Luxations can occur in three ways in the upper cervical spine in rheumatoid arthritis: (1) forward dislocation of atlas on axis, the common variety; (2) vertical luxation of the axis; 4910 (3) backward displacement of atlas on the axis. ${ }^{11}$ Group 1 depends essentially on ligamentous laxity or destruction of soft tissues, groups 2 and 3, much smaller than 1 , on destruction of bone and cartilage. Though upward migration of the odontoid process into the foramen magnum, which happened in $5 \%$ of 76 cases in one series, 12 may prove fatal, serious neurological sequelae do not necessarily occur even with extreme degrees of vertical subluxation.10 Considering how frequent luxations are in this common disorder it is extraordinary that serious and fatal neurological complications are not commoner than they are. The answer probably lies in the destruction of the odontoid process by the disease and the adaptability of softened and luxated tissues in the area.

Cervical luxations without symptoms are best treated conservatively, care being taken to avoid sudden or violent forward flexion of head on neck, as in a barber's or dentist's chair, when sneezing, or on the anaesthetic table. The case for collars in certain conditions, as in vertical subluxations, is still sub judice. They are often given by physicians with the aim of preventing fatal complications and often given up by the patient as being uncomfortable and unhelpful. Surgical cervical fusion ${ }^{13-15}$ may save life occasionally but is necessary only in a minority of cases.

Physicians looking after patients with severe rheumatoid arthritis should bear in mind neurological changes in the upper cervical region. Neurological signs and symptoms may be grafted onto an already complicated clinical picture.

1 Garrod, A. E., A Treatise on Rheumatism and Rheumatoid Arthritis. London, C. Griffen, 1890.

2 Sharp, J., Purser, D. W., and Lawrence, J. S., Annals of the Rheumatic Diseases, 1958, 17, 303 .

3 Scott, J. T., in Textbook of the Rheumatic Diseases, ed. W. S. C. Copeman, 4th edn., p. 650. London, Livingstone, 1969.

Sharp, J., and Purser, D. W., Annals of the Rheumatic Diseases, $1961,20,47$.

5 Conlon, P. W., Isdale, I. C., and Rose, B. S., Annals of the Rheumatic Diseases, 1966, 25, 120.

6 Boyle, J. A., and Buchanan, W. W., Clinical Rheumatology, p. 100. Oxford, Blackwell Scientific, 1971.

7 Miekle, J. A. K., and Wilkinson, M., Annals of the Rheumatic Diseases, $1971,30,154$.

8 Ball, J., and Sharp, J., in Modern Trends in Rheumatology, 2, p. 117, ed. A. G. S. Hill. London, Butterworths, 1971.

9 Smith, P. H., Benn, R. T., and Sharp, J., Annals of the Rheumatic Diseases, 1972, 31, 431. 10 Swinson, D. R., Hamilton, E. D., Mathews, J. A., and Yates, D. A. H.,

11 Isdal- I. C., and Corrigan, A. B., Annals of the Rheumatic Diseases, $1970,29,6$.

12 Mathews, J. A., Annals of the Rheumatic Diseases, 1969, 28, 260.

13 Cregan, J. C. F., Annals of the Rheumatic Diseases, 1966, 25. 242.

15 Hopkins, J. S., fournal of Bone and foint Surgery, 1967, 49B, 46.

\section{Crossing the Gap}

One essential need when supplying aid to a developing country is that the recipient should be able to use it to its full extent. The contrast between the technical proficiency of the donor country and the simple, largely peasant economy which it may be trying to help can represent a gap that jet airplanes fail to cross. Something more than mere delivery is required of the donor-notably understanding, instruction, and imagination. On these grounds a scheme described this week by Sir John Richardson (page 806) and the subject of an appeal (advertisement page $x$ ) deserves special commendation.

As a result of the initiative some six years ago of Dr. James Burton and Sir Arthur, now Lord, Porritt the Joint Mission Hospital Equipment Board came into existence. Its object is to collect unwanted medical equipment in Britain, restore it when necessary to first-class condition, and supply it to hospitals in developing countries, mostly those run on a missionary or charitable basis. It is at present sending equipment to over 600 hospitals in 65 countries. Among the suppliers in Britain have been private individuals, the armed Forces, the National Health Service, and commercial firms. In some cases restocking has allowed them to get rid of new equipment in this way, but when the equipment has been used and is in need of restoration the board ensures that it is brought into first-class condition before being sent overseas. Anyone responding to the appeal now published will be helping a thoroughly worthwhile cause, for the equipment is needed in the developing countries and will go to people qualified to use it, the devoted medical men and women working in hospitals that are often remote and always short of supplies. 